\title{
BASIC HEALTH CARE FOR EVERYONE
}

In its September 1975 issue, International Review drew attention to the problem of the rising costs of providing health care, which in the developing pountries have reached truly excessive levels. The article referred to the cublication of a book following a symposium organized by the Henry Dunant Institute on this subject. ${ }^{1}$ As pointed out by the reviewer of the book, Mr. B. Elliot, "the healthiness of the population dismally fails to improve in proportion to more spending on care". It is only through a better organization of care services to the community that it will be possible to provide care to the greatest number of people. "The problem of costs, now critical in several countries, is thus associated with larger questions."

It is this aspect, too, that was examined, among other questions, at a meeting of the League's Nursing Advisory Committee some months ago. In an article in Panorama, ${ }^{2}$ extracts of which are reproduced below, Muriel Skeet, Nursing Adviser of the British Red Cross Society, explained what should be done and suggested what were the lessons to be drawn from that meeting. Red Cross nurses and nursing services, in most countries basically hospital oriented, should shift their sights towards the community. It was in the community, rather than in the specialized services and in "sensational" medical successes, that nursing personnel could contribute most effectively to the development of care and of better medical protection for the whole population.

"The magnitude of the world's health problems is difficult to comprehend. In spite of the strides in medicine and technology, the health status of millions of people remains low. This is especially so of the

1 “The Health Care Cost Explosion: Which Way Now?", 1975.

${ }^{2}$ League of Red Cross Societies publication, Geneva, 1975/3. 
majority of people living in the disadvantaged areas of many countries of the world."

This statement was quoted by Dr. Aleya El Bindari Hammad, Scientist/Nursing and Public Health Officer, Division of Strengthening of Health Services, of the World Health Organization at the League's Nursing Advisory Committee Meeting held in Geneva, 17th-19th April.

Unfortunately the general picture of the world is of an expensive health industry catering not for the promotion of health, but for the unlimited application of disease technology. The very health services which should be contributing to the health status of people are obsessed by building and staffing disease-oriented institutions.

It is reported that in one sophisticated city, more than 70 per cent of all so-called health expenditure is used on people who are going to die within the next twelve months. Countries further down the development scale are imitating this perversion. In one developing country, 80 per cent of the health budget of one province is being used to support one teaching hospital, whilst on the periphery, one general-purpose dispensary is supposed to achieve complete health coverage for half a million people. These examples are not exceptional, they are ordinary. In addition, aspects contributing to human well-being such as education, communication, social organization, agriculture and community motivation and involvement have been neglected.

Health is not just the absence of disease and infirmity, it is, according to the definition adopted by W.H.O., a state of physical, mental and social well-being.

As one of the objectives of both the Red Cross movement and of the nursing profession is "the improvement of health, the prevention of disease and the mitigation of suffering throughout the world", it is not surprising that at their meeting in 1973 members of the League's Nursing Advisory Committee expressed great concern on learning that 80 per cent of the world's population was still without health coverage. They considered it a matter of urgent importance to set up an Expert Nursing Group to consider ways in which the National Red Cross Societies could help meet this demand in their own countries.

A preliminary review began in 1973 and at the most recent meeting of the Nursing Advisory Committee the report prepared by that Expert Group was adopted.

At its final session the League's Advisory Committee recommended that each National Society should discover the health needs of its own 
country. To do this, people themselves must be asked what they want or need; priorities or solutions should not be forced upon them. Often the needs are simple and basic. Analyses by teams of economists, engineers, sociologists, epidemiologists and the like are not required. Villagers know the needs themselves.

Having discovered the needs, plans must be made to meet them and the last pages of the Report set out suggested "Action Strategy".

The Nursing Advisory Committee endorsed the recommendation that the Red Cross should act as a catalyst and activator in the development of primary health care services.

It also recommended that the knowledge, experience and skills of the nurse be used at all levels of policy making and programme planning.

There was also a call for the co-ordination of all resources concerned with health care, including those outside the Red Cross as well as all professions and disciplines within it.

It emphasized the importance of doctors' and nurses' having a community-based education and becoming far less hospital-orientated. In the past, training of all health personnel was primarily related to medical and institutional care and was therefore irrelevant to tasks and functions outside institutional settings: emphasis was given to medical, rather than to overall health care. This had to be changed if the health status of people was to be raised. 